\title{
A Maximum Power Point Tracking Algorithm of Load Current Maximization-Perturbation and Observation Method with Variable Step Size
}

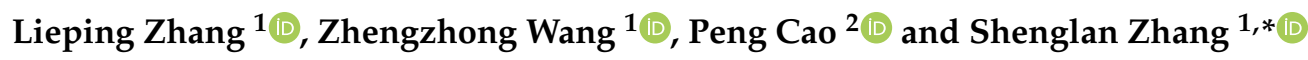 \\ 1 College of Mechanical and Control Engineering, Guilin University of Technology, Guilin 541004, China; \\ zlp_gx_gl@163.com (L.Z.); Jyanewzz@outlook.com (Z.W.) \\ 2 School of Automation, Guangdong University of Technology, Guangzhou 510006, China; \\ lhcaopeng_2010@163.com \\ * Correspondence: zsl@glut.edu.cn
}

Received: 15 January 2020; Accepted: 1 February 2020; Published: 5 February 2020

\begin{abstract}
A photovoltaic power supply with a simple structure and high tracking efficiency is needed in self-powered, wireless sensor networks. First, a maximum power point tracking (MPPT) algorithm, including the load current maximization-perturbation and observation (LCM-P\&O) methods, with a fixed step size, is proposed by integrating the traditional load current maximization (LCM) method and perturbation and observation ( $\mathrm{P} \& \mathrm{O}$ ) method. By sampling the changes of load current and photovoltaic cell input current once the disturbance is applied, the pulse width modulation (PWM) regulation mode, i.e., increasing or reducing, can be determined in the next process. Then, the above algorithm is improved by using the variable step size strategy. By comparing the difference between the absolute value of the observed current value and the theoretical current value at the maximum power point of the photovoltaic cell with the set threshold value, the variable step size for perturbation is determined. MATLAB simulation results show that the LCM-P\&O method, with a variable step size, has faster convergence speed and higher tracking accuracy. Finally, the two MPPT algorithms are tested and analyzed under constant voltage source input and indoor fluorescent lamp illumination through an actual circuit, respectively. The experimental results show that the LCM-P\&O method with variable step size has a higher tracking efficiency, about $90 \%-92 \%$, and has higher stability and lower power consumption.
\end{abstract}

Keywords: photovoltaic cell; maximum power point tracking; perturbation and observation method; load current maximization method; wireless sensor network; variable step size

\section{Introduction}

The traditional wireless sensor network (WSN) usually uses dry cells and other disposable storage for its energy supply. Due to the limited storage capacity of the dry cell, it is difficult to provide long-term, stable operations for the sensor nodes in the remote area, and further affects the performance of WSN [1]. As a low-cost, safe and clean energy supply, photovoltaic power supply is widely used in environmental monitoring, intelligent transportation, and other fields [2,3]. With the help of a photovoltaic power supply device and rechargeable lithium battery, the wireless sensor node can collect the solar energy from nature and provide stable energy supply for sensor nodes. Thus, it overcomes the energy limitation brought by the independent power supply of the dry cell and provides the possibility for the long-term, stable operation of WSN [4].

In photovoltaic power generation, there are three main ways to improve the power generation efficiency: (1) improve the performance of solar panel, (2) improve the maximum power point tracking 
(MPPT) method, and (3) improve a series of converters, controllers, and inverters in a photovoltaic grid-connected system. Among them, the improved MPPT algorithm has obvious effects and a low cost, which has become the first choice for scholars to improve the efficiency of photovoltaic power generation $[5,6]$. The MPPT algorithm detects the generation voltage of the photovoltaic cells in real-time and adjusts the output voltage to make the photovoltaic cells work in the maximum output state. Due to the characteristics of photovoltaic cells and the complexity of photovoltaic power generation circuits, the output characteristics of photovoltaic cells will constantly change under different sunlight intensities and ambient temperatures, and the maximum power output is obtained under a certain voltage. Therefore, the MPPT algorithm is particularly important in improving the energy conversion efficiency of photovoltaic cells.

At present, the main MPPT algorithms include: the constant voltage method [7], conductance increment method [8], perturbation and observation (P\&O) method [9], load current maximization method (LCM) [10], fuzzy control method and neural network method [11], etc. The traditional constant voltage method is the simplest way to realize the maximum power tracking of photovoltaic cells. While the constant voltage method only works under the most appropriate voltage, its effectiveness is limited in the field where the environment changes dramatically [7]. While the traditional conductance increment method has a higher steady-state accuracy and certain dynamic response ability, the problem of the tracking speed and steady-state accuracy remains and is difficult to balance [12]. The traditional $\mathrm{P} \& O$ method has the advantages of a simple principle, few measured parameters, and easy realization. However, when the output voltage is near the maximum power point, the direction of the voltage perturbation is easy to be misjudged, and the steady-state accuracy cannot meet the demand [13]. The advantages of LCM are its simple circuit structure and only current or voltage is needed. However, the maximum power point obtained by this method is only the sub-optimal power point of photovoltaic cells [10]. The fuzzy control method and neural network method have the advantages of a relatively simple mathematical model, good anti-interference performance, and flexibility. However, they have they disadvantages of a complex algorithm, large calculation and difficult implementation, which is not suitable for low-power wireless sensor nodes [14,15]. In general, all kinds of MPPT algorithms have their own advantages and disadvantages and their corresponding application occasions. Many researchers have improved the traditional MPPT method and its derived algorithm. The improvement strategy mainly includes two aspects: one is to improve the traditional MPPT algorithms and its derivative algorithms [16,17], and the other is to combine the advantages of different MPPT algorithms and to derive a new MPPT algorithm $[18,19]$.

The P\&O method is one of the most used methods to realize MPPT technology in engineering, and it is also one of the most used MPPT algorithms at present. Reference [20] proposed a new artificial neural network P\&O MPPT algorithm based on variable step size, and gave the corresponding simulation and implementation method. To eradicate the limitations of conventional fixed step-size, Reference [21] proposed a variable step size P\&O MPPT algorithm for the optimal power extraction of a multi-phase, permanent magnet synchronous generator based wind generation system. The existing P\&O MPPT algorithm improves the contradiction of tracking accuracy and tracking time by changing the step size, but does not consider the energy consumption. Therefore, this $\mathrm{P} \& \mathrm{O}$ method has some limitations in practical applications of photovoltaic power supply in WSN. Fortunately, the load maximization method can effectively solve this problem. Reference [22] proposed a simple maximum power point tracking method for a series-connected DC-DC converter module of photovoltaic power conditioning systems. This approach reduced the energy consumption through simple output voltage sensing, not power calculation. Reference [23] proposed a constant voltage maximum power point algorithm that automatically adjusts the reference voltage to account for varying environmental conditions. The above load maximum methods were mostly used to detect the voltage, and were similar to the load voltage method. However, in our study, when the photovoltaic cell is used to charge the lithium battery, the working state of the lithium battery is similar to the current source. Thus, in the charging process, when the current of the lithium battery increases, the output power 
of the photovoltaic cell also increases. When the charging current reaches the maximum value, the photovoltaic cell also realizes the maximum energy output. Therefore, it is appropriate to detect changes in current. Thus, the LCM method is only suitable for our MPPT. Reference [24] proposed a dynamically self-adaptive LCM technique to eliminate inflexibility over characteristic variations of PV arrays, where only the converter's output current is sensed for control purposes. However, the BOOST converter circuit was used to realize MPPT, and that method was not suitable for the low voltage applications of WSN. High conversion efficiency and low power consumption are the basic requirements in the photovoltaic self-supply application of WSN. How to find an effective MPPT algorithm to meet the demand is the main purpose of our study.

An LCM tracking algorithm with variable step size is proposed in this paper. This algorithm combines the advantages of the P\&O method and the common LCM method. It does not need to calculate power to determine the disturbance direction, and only needs to sample the load current. Then, the dynamic MPPT is realized by adjusting the reference current value to approach the maximum power point gradually. The Matlab/Simulink simulation results show that the maximum power point waveform amplitude of the proposed algorithm is smaller, the convergence speed is faster, the tracking accuracy is higher, and the proposed algorithm has certain theoretical value. In order to verify the effectiveness of the proposed algorithm, the hardware circuit of MPPT is designed based on the proposed algorithm. As the MPPT circuit uses a BUCK circuit, the load voltage does not change much. The maximum power point efficiency of the photovoltaic cell can only be analyzed by sampling the load current. The performance of the MPPT circuit is analyzed by simulating the voltage of the photovoltaic cell with a constant voltage source and adjusting the illumination intensity of the solar lamp. The experimental results show that the MPPT circuit can track the maximum power point of the photovoltaic cell in real time, and has good tracking precision under static conditions and a fast response speed under dynamic conditions; it can also be used in a kind of low-power system similar to WSN.

\section{Analysis of Solar Photovoltaic Cell}

\subsection{Modeling of Solar Photovoltaic Cell}

Under the condition of solar illumination, the free electrons and holes in the solar photovoltaic panels move to the two poles of the panels, respectively, making one end of the panel have a positive charge and the other end to have a negative charge. In this way, the formation of the positive and negative poles also causes the appearance of the potential difference. Solar photovoltaic cells use this 'photovoltaic effect' principle to convert light energy into electrical energy [25]. The equivalent circuit diagram of the solar photovoltaic cell in the actual state is shown in Figure 1 [26]. As shown in Figure 1, $I_{p c}$ is the current generated when sunlight shines on the photovoltaic cell, $I_{P N}$ is the current passing through the Diode branch, $R_{L}$ is the load, $I_{L C}^{\prime}$ is load current, $U_{L V}$ is load voltage, $R_{M A}$ is the resistance of the photovoltaics material itself, $R_{P A}$ is the internal resistance due to micro-scratches produced during the fabrication of photovoltaic cell, and $I_{P A}$ is the current passing through the $R_{P A}$ branch.

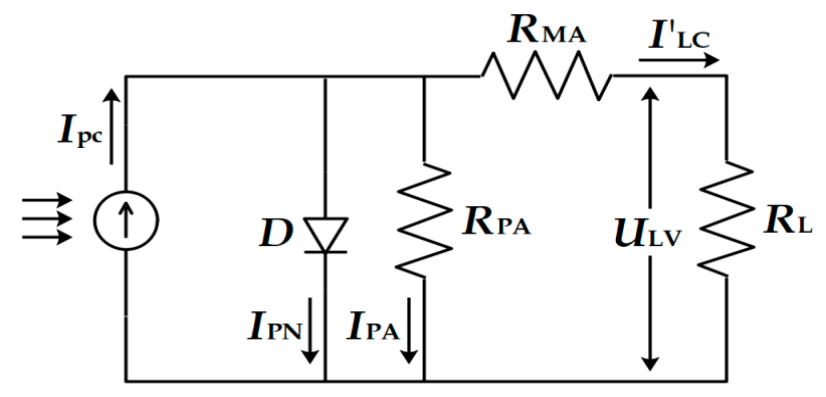

Figure 1. Actual state equivalent circuit of photovoltaic cell. 
The expression of the load current $I_{L C}^{\prime}$ can be obtained from Figure 1 and Kirchoff's current law (KCL) theorem, as shown in Equation (1):

$$
I_{L C}^{\prime}=I_{p c}-I_{P N}-I_{P A}
$$

The expression of $I_{p c}$ can be obtained from the photocurrent principle of solar photovoltaic cells, as shown in Equation (2):

$$
I_{p c}=\frac{I_{S C} S}{G_{r}}+G\left(T-T_{r}\right)
$$

where $I_{S C}$ is the short-circuit current of the photovoltaic cell, $S$ is the illumination area of the photovoltaic cell, $G_{r}$ is the reference standard illumination intensity, $G$ is the illumination intensity of the sun, $T$ is the panel temperature of the photovoltaic cell, and $T_{r}$ is the reference standard temperature.

The current $I_{P A}$ flowing through the resistance in the solar photovoltaic cell can be expressed by Equation (3):

$$
I_{P A}=\frac{U_{L V}+I_{L C}^{\prime} R_{M A}}{R_{P A}}
$$

$R_{M A}$ is generally less than $1 \mathrm{ohm}$, and $R_{P A}$ generally selects a resistance of more than 1 kiloohm. Thus, $R_{M A}$ and $I_{P A}$ can be ignored. The simplified mathematical model is shown in Equation (4):

$$
I_{L C}^{\prime}=\frac{I_{S C} S}{G_{r}}+G\left(T-T_{r}\right)-I_{S}\left[\exp \left(\frac{q U_{L V}}{A K T}\right)-1\right]
$$

When the photovoltaic cell is short-circuited, the photocurrent can be approximately equal to the short-circuit current, that is $I_{p c}=I_{S C}$. Let $C_{1}=\frac{I_{S}}{I_{S C}}, C_{2}=\frac{q}{A K T}$, where $C_{1}$ and $C_{2}$ are uncertain coefficients; Equation (4) can be simplified as the expression shown in Equation (5):

$$
I_{L C}^{\prime}=I_{S C}\left\{1-C_{1}\left[\exp \left(\frac{U_{L V}}{C_{2}}\right)-1\right]\right\}
$$

According to the proportional relationship between the parameters in the standard environment and the parameters in the actual environment, the output characteristics of photovoltaic cells with different light intensities and temperature changes can be obtained [27], and the relationship is shown in Equations (6)-(12).

$$
\begin{gathered}
\Delta G=G-G_{r} \\
\Delta T=T-T_{r} \\
I_{m}=I_{m}^{\prime} \cdot \frac{G}{G_{r}} \cdot(1+a \Delta T) \\
U_{m}=U_{m}^{\prime} \cdot \ln (e+b \Delta G) \cdot(1-c \Delta T) \\
U_{O C}=U_{O C}^{\prime} \cdot \ln (e+b \Delta G) \cdot(1-c \Delta T) \\
I_{S C}=I_{S C}^{\prime} \cdot \frac{G}{G_{r}} \cdot(1+a \Delta T) \\
P_{P V}=P_{r} \cdot \frac{G}{G_{r}} \cdot[1+K \Delta T] .
\end{gathered}
$$

In Equations (6)-(12), $\Delta T$ is the difference between the actual temperature and the standard temperature, $\Delta G$ is the difference between the actual light intensity and the standard light intensity, $I_{S C}$ is the actual short-circuit current, $U_{O C}$ is the actual open-circuit voltage, $I_{m}$ is the actual peak current, $U_{m}$ is the actual peak voltage, $I_{S C}^{\prime}$ is the short-circuit current under the standard condition, $U_{O C}^{\prime}$ is the open-circuit voltage under the standard condition, $I_{m}^{\prime}$ is the peak current under the standard condition, $U_{m}^{\prime}$ is the peak voltage under the standard condition, $T$ is the ambient temperature in centigrade, $T_{r}$ is 
the temperature under the standard condition, $G$ is the light intensity, $T_{r}$ is the light intensity under the standard condition, $P_{P V}$ is the actual output power of the photovoltaic cell, $P_{r}$ is the output power of the photovoltaic cell under the standard condition, and $a, b$, and $c$ are the compensation coefficients, with the values of $0.0025,0.0005$, and 0.00288 , respectively [28].

\subsection{Output Characteristics of Solar Photovoltaic Cell}

According to the routine, the standard temperature and light intensity in the research are $25{ }^{\circ} \mathrm{C}$ and $1000 \mathrm{~W} / \mathrm{m}^{2}$. The parameters of a brand $12 \mathrm{~V} 3 \mathrm{~W}$ polysilicon photovoltaic cell under the standard temperature and standard light intensity are as follows: $U_{O C}=12.7 \mathrm{~V}, I_{S C}=0.42 \mathrm{~A}, U_{m}=8.5 \mathrm{~V}, I_{m}=$ $0.35 \mathrm{~A}$. Using the simulation model of the solar photovoltaic cell established by MATLAB/Simulink, we can simulate the output characteristics of photovoltaic cell. In the experiment, when the simulated temperature is set at $25{ }^{\circ} \mathrm{C}$ and the light intensity is taken as $200 \mathrm{~W} / \mathrm{m}^{2}, 400 \mathrm{~W} / \mathrm{m}^{2}, 600 \mathrm{~W} / \mathrm{m}^{2}$, $800 \mathrm{~W} / \mathrm{m}^{2}, 1000 \mathrm{~W} / \mathrm{m}^{2}$, and $1200 \mathrm{~W} / \mathrm{m}^{2}$, respectively, the voltage-power(U-P) characteristic curves, as shown in Figure 2a, and the voltage-current (U-I) characteristic curves, as shown in Figure 2b, can be obtained.

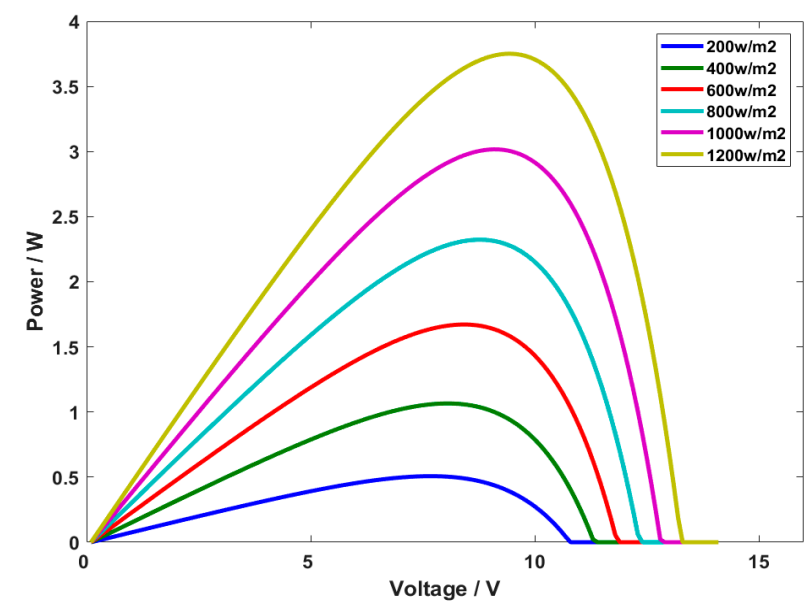

(a)

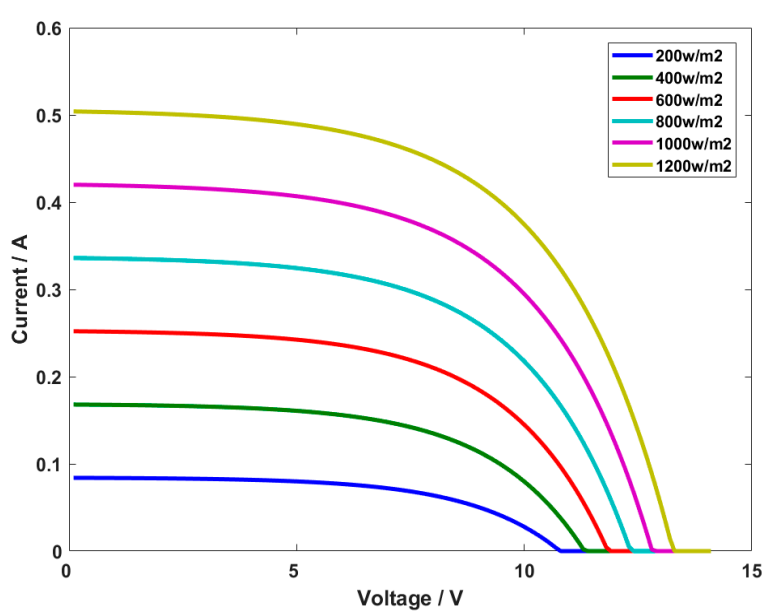

(b)

Figure 2. Output characteristic curves of photovoltaic cell affected by light intensity. (a) U-P characteristic curves; (b) U-I characteristic curves.

In Figure 2a, each curve has its highest point (i.e., the maximum power point), and when the light intensity increases, in turn, the maximum power increases gradually, but the voltage change at the maximum power point does not fluctuate much. Similarly, it can be seen from Figure $2 b$ that, with the increase of light intensity, the short-circuit current $I_{S C}$ increases significantly, but the open-circuit voltage $U_{O C}$ changes slightly.

From the above simulation results of the output characteristics of solar photovoltaic cells, it can be seen that the change of the radiation intensity of photovoltaic cells has a more significant impact on its output current. Under a certain light intensity, the output power of the photovoltaic cell has only one maximum power point, which is the theoretical basis of MPPT.

\section{LCM-P\&O Method and Its Improvement}

\subsection{LCM-PEO Method with Fixed Step Size}

In the traditional $\mathrm{P} \& \mathrm{O}$ method, the light intensity, temperature, and other external environment elements are assumed to be constant; a small perturbation is applied to the voltage or current of the photovoltaic cell, the output voltage and current of the working point before and after the perturbation 
are detected, and the corresponding power is calculated. By observing the power changes of these two working points, we can judge whether the current working point is on the left or the right of the maximum power point. If the power increases, the perturbation is applied in the direction of the previous perturbation. If the power decreases, the perturbation is applied in the opposite direction of the previous perturbation until the working point finally approaches the maximum power point. Obviously, the P\&O method needs to collect the output voltage and current data of photovoltaic cells, respectively, and the perturbation direction can only be determined by comparing the calculated power value. The selection of the perturbation value of the P\&O method has a great influence on the accuracy and convergence speed of the algorithm. If the perturbation value is smaller, the accuracy will be improved, but the convergence speed will be very slow. If the perturbation value is larger, the convergence speed will be improved, but the accuracy will be lower.

According to the above characteristics of photovoltaic cells, since the change of light intensity is generally regular, the voltage fluctuation trend of photovoltaic cells can be predicted. At the same time, in order to ensure that the output of photovoltaic cells can meet the voltage demand in most weather, the BUCK circuit is used as the energy transfer circuit of MPPT circuit in this study. Therefore, the voltage of the photovoltaic cell before and after MPPT has almost no change. In this way, we can only track the maximum power point efficiency of photovoltaic cells by monitoring the change of load terminal current. Therefore, we integrate the idea of LCM into the traditional P\&O method and form the MPPT algorithm, which is suitable for the practical application of self-powered wireless sensor network. We call it load current maximization-perturbation and observation (LCM-P\&O) method with fixed step size. The realization process of the LCM-P\&O method with fixed step size is as follows: First, measure the voltage $V_{N}$ and current $I_{N}$ at the output end of the photovoltaic cell, and make the current $I_{r e f}=I_{N}$ at the maximum power point. By applying the perturbation signal through the pulse width modulation (PWM), the duty cycle of Field Effect Transistor (FET) is changed, so that the current passing through the load changes and the perturbation current is generated. In this way, the direction of the next perturbation can be determined by monitoring the current at the load end and the current at the input end of the photovoltaic cell. The specific implementation process is shown in Figure 3.

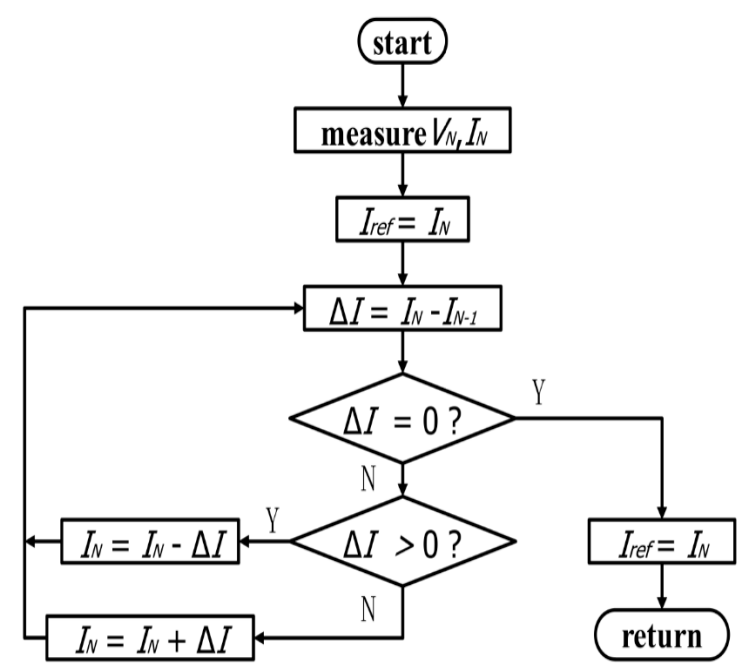

Figure 3. Realization flow of LCM-P\&O method with fixed step size.

\subsection{LCM-PEO Method with Variable Step Size}

According to the previous analysis, it can be seen that the realization process of the LCM-P\&O method with fixed step size is similar to that of the traditional P\&O method, and a perturbation value needs to be selected. Therefore, the method also has the problem of accuracy and convergence speed can not be achieved at the same time. However, compared with the traditional P\&O method, the 
algorithm does not need to calculate the power to determine the direction of perturbation, so the amount of calculation is less, and the energy consumption will be reduced accordingly.

To improve the tracking accuracy and convergence speed, we improved the fixed step strategy in the above algorithm, so that the step can be variable. The flow chart of LCM- P\&O method with variable step size is shown in Figure 4. In Figure 4, the fixed current value at the maximum power point of the photovoltaic cell is $I_{R}$, the D-value between the observed current value $\mathrm{I}_{\mathrm{N}}$ and $\mathrm{I}_{R}$ is calculated, and its absolute value is compared to the fixed step size $\Delta a$. When $\left|I_{R}-I_{N}\right|<\Delta a$, a small step $\Delta I_{L}$ is used as the perturbation value. When $\left|I_{R}-\mathrm{I}_{\mathrm{N}}\right|>\Delta a$, a large step $\Delta I_{B}$ is used as the perturbation value. When the environment of WSN node changes a lot, the error value of $I_{R}$ will be larger. Therefore, when tracking each maximum power point, the current value of the new maximum power point is used to cover the $I_{R}$. Such a strategy not only improves the tracking accuracy of maximum power point, but also improves the convergence speed.

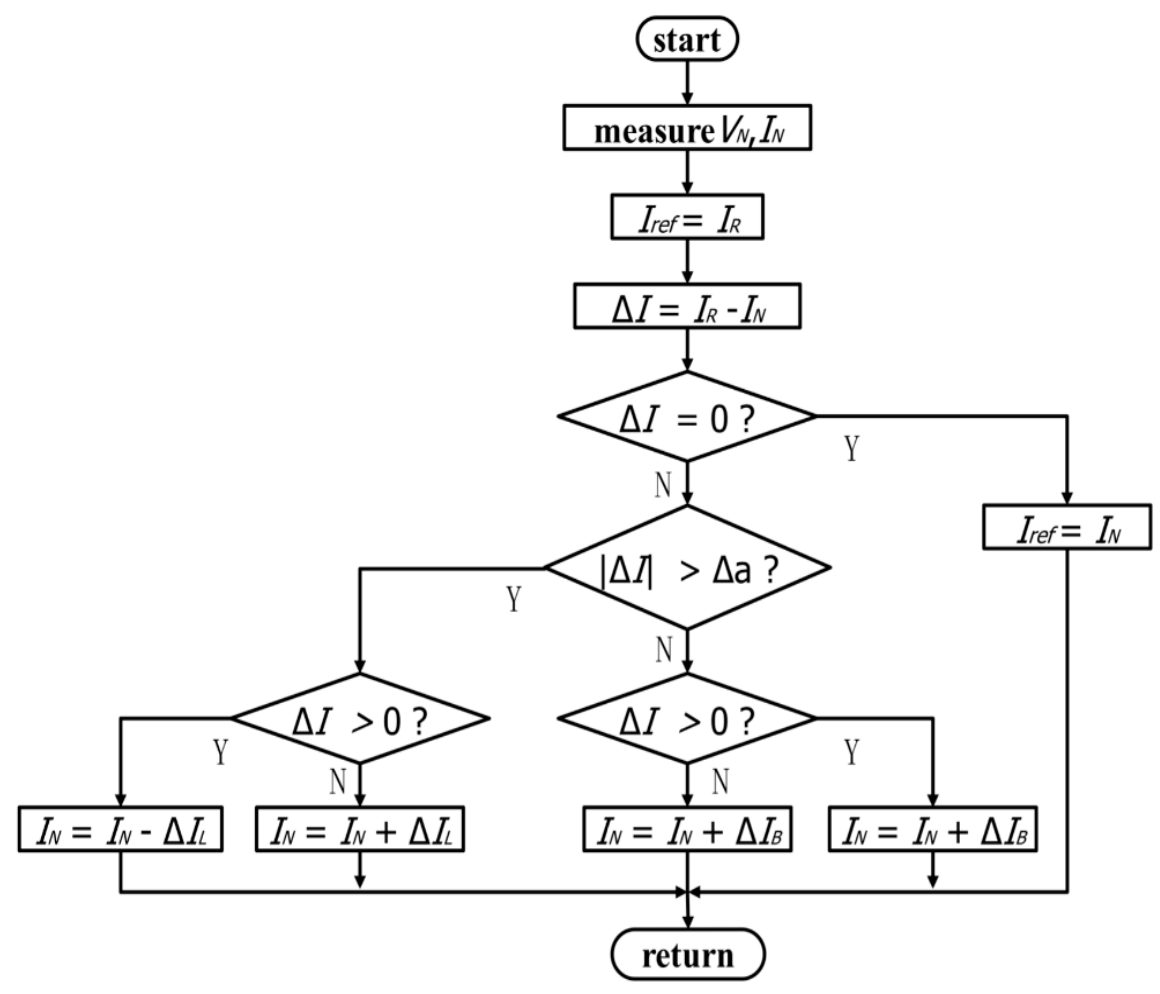

Figure 4. Realization flow of the LCM-P\&O method with variable step size.

\section{Simulation and Experiment Verification}

\subsection{Experimental Simulation}

According to the previous photovoltaic cell model and MPPT strategy, we established the MPPT algorithm simulation model based on MATLAB/Simulink, as shown in Figure 5. According to the previous photovoltaic cell model and the MPPT strategy, we established the MPPT algorithm simulation model based on MATLAB/Simulink, as shown in Figure 5. We use the simulation model to compare the LCM-P\&O method with fixed step size and the LCM-P\&O method with a variable step size. 


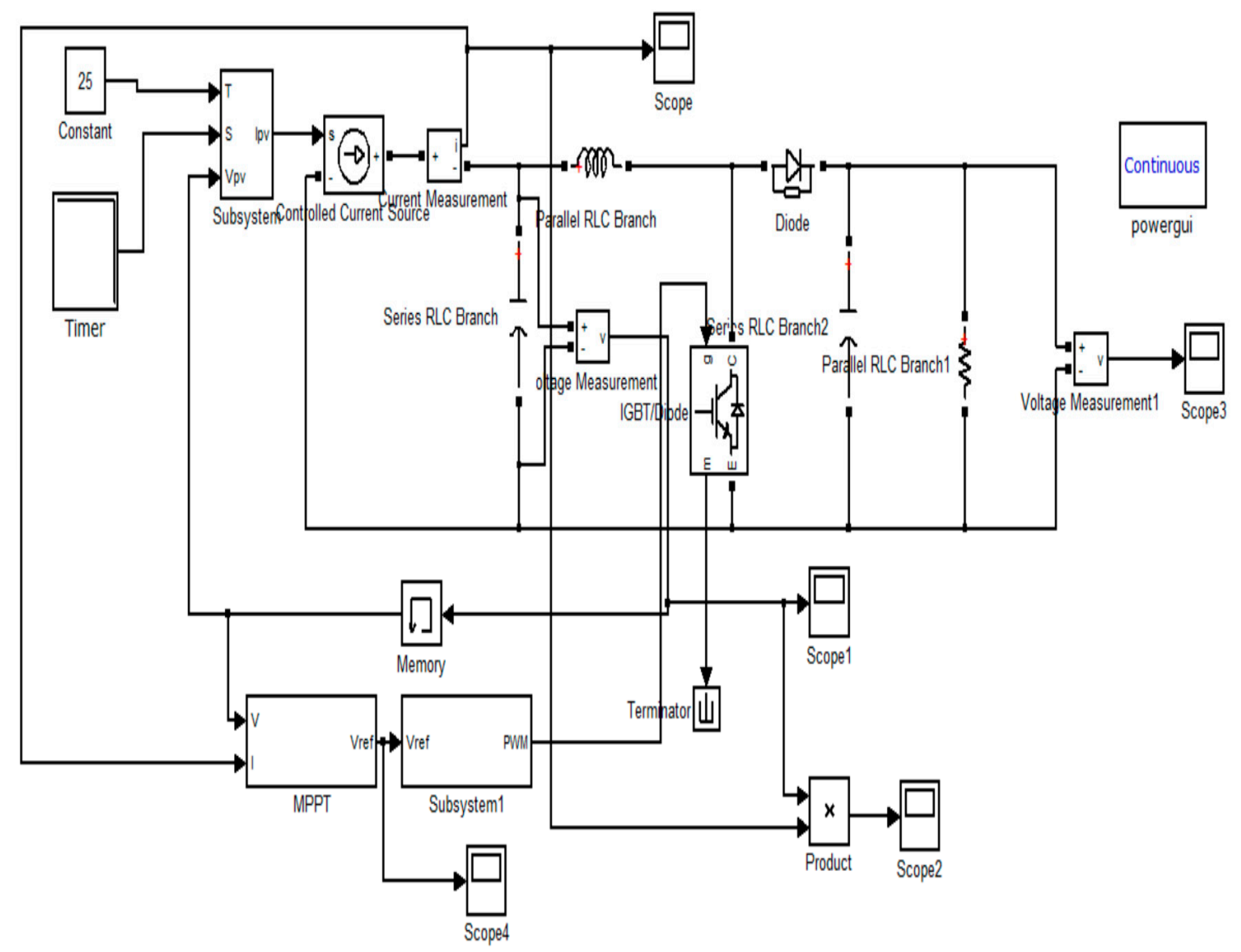

Figure 5. MATLAB/Simulink simulation model of MPPT algorithm.

The experimental conditions of MPPT are as follows: Ambient temperature is $25^{\circ} \mathrm{C}$, the light radiation intensity is $1000 \mathrm{~W} / \mathrm{m}^{2}$. In the experiment, at $0.1 \mathrm{~s}$, the radiation intensity of ambient light suddenly decreased from $1000 \mathrm{~W} / \mathrm{m}^{2}$ to $600 \mathrm{~W} / \mathrm{m}^{2}$. The output power of the two methods is compared. The output power waveform of the two algorithms is shown in Figure 6.

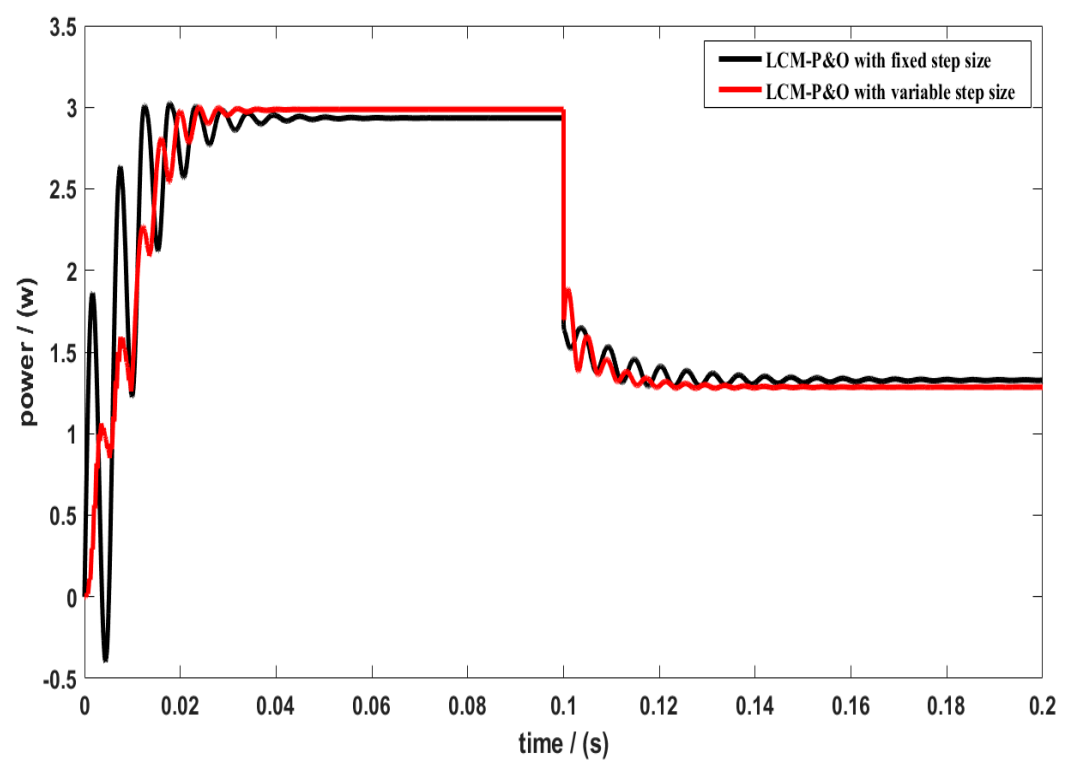

Figure 6. Output power waveform of two MPPT algorithms. 
In Figure 6, when the LCM-P\&O method with fixed step size tracks the maximum power point, the fluctuation amplitude is relatively large, while that of the LCM-P\&O method with variable step size is relatively small. The power waveform of the LCM-P\&O method with fixed step size tends to be stable after $0.05 \mathrm{~s}$, while the LCM-P\&O method with variable step size tracks MPP at $0.03 \mathrm{~s}$. Therefore, the LCM-P\&O method with variable step size improves the MPPT tracking speed and reduces the amplitude of the waveform. At the same time, when the light radiation intensity suddenly decreases from $1000 \mathrm{~W} / \mathrm{m}^{2}$ to $600 \mathrm{~W} / \mathrm{m}^{2}$, the LCM-P\&O method with variable step size can trace the maximum power point in $0.12 \mathrm{~s}$, while the LCM-P\&O method with fixed step size fluctuates slightly after $0.15 \mathrm{~s}$. Therefore, compared with the LCM-P\&O method with fixed step size, the LCM-P\&O method with variable step size has smaller amplitude, faster convergence speed and higher tracking accuracy. At the same time, it can also be found that, when the light radiation intensity is reduced to $600 \mathrm{~W} / \mathrm{m}^{2}$, the overall power of the photovoltaic cell will be greatly reduced due to the loss of its circuit. It shows that the power of photovoltaic cells is greatly affected by the change of light radiation intensity.

\subsection{Experimental Verification}

\subsubsection{Design of MPPT Circuit}

The MPPT circuit consists of three parts: PWM perturbation generation circuit, photovoltaic cell current, and voltage detection circuit and BUCK circuit.

The PWM perturbation generating circuit in this paper is shown in Figure 7. The circuit is mainly realized by the half bridge driver IR2104. As the input voltage range required by the VCC pin end of IR2104 is 8-20 V, we use the photovoltaic cell output as the input power of VCC terminal directly. The final PWM waveform of IR2104 is output by the vs. pin, and the PB7 pin and PC6 pin of the control chip are used as the input control terminals of IR2104 chip. The HO and LO pins of IR2104 connect two si2302-MOS FET to drive the on and off of Q1 and Q2.

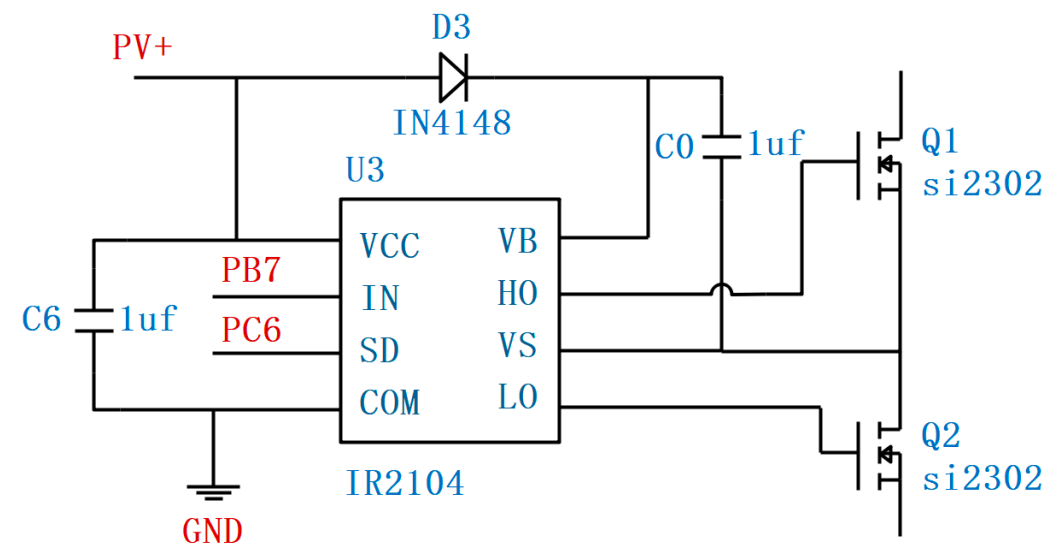

Figure 7. PWM perturbation generating circuit.

The current and voltage detection circuit of the photovoltaic cell in the research is shown in Figure 8. The precision current detection amplifier MAX471 mainly realizes the circuit. A diode D1 is connected between the photovoltaic cell and the MAX471 to prevent the current flowing backward into the photovoltaic cell. In the circuit, the out pin of MAX471 is the current output terminal, R1, and $\mathrm{C} 1$ have the function of amplitude modulation and filtering, R2, R3, and C2 have the function of voltage stabilization and filtering. The control chip detects the output current of the photovoltaic cell by collecting the output current of MAX471 through the PA7 pin, and detects the output voltage of the photovoltaic cell through PA2 pin. 


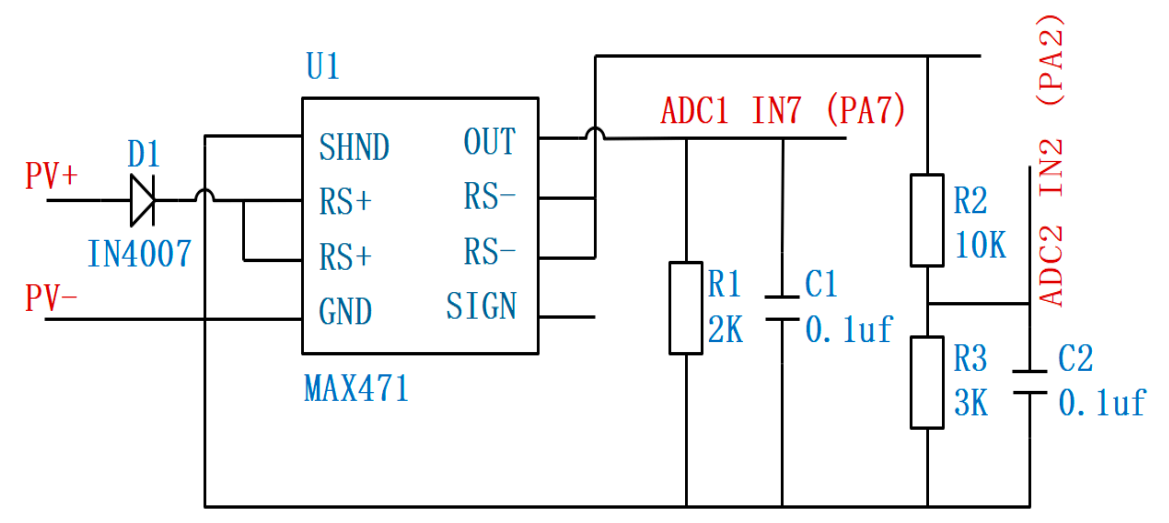

Figure 8. Current and voltage detection circuit of the photovoltaic cell.

The BUCK circuit of this paper is shown in Figure 9. The circuit consists of $33 \mu \mathrm{H}$ inductance $\mathrm{L}$, $220 \mu \mathrm{F}$ capacitance C, and freewheel diode D2. Q1 and Q2 MOSFET are controlled by IR2104 through the output of the PWM perturbation. The current of the photovoltaic cell is detected by MAX471, and PWM perturbation is adjusted according to its current change.

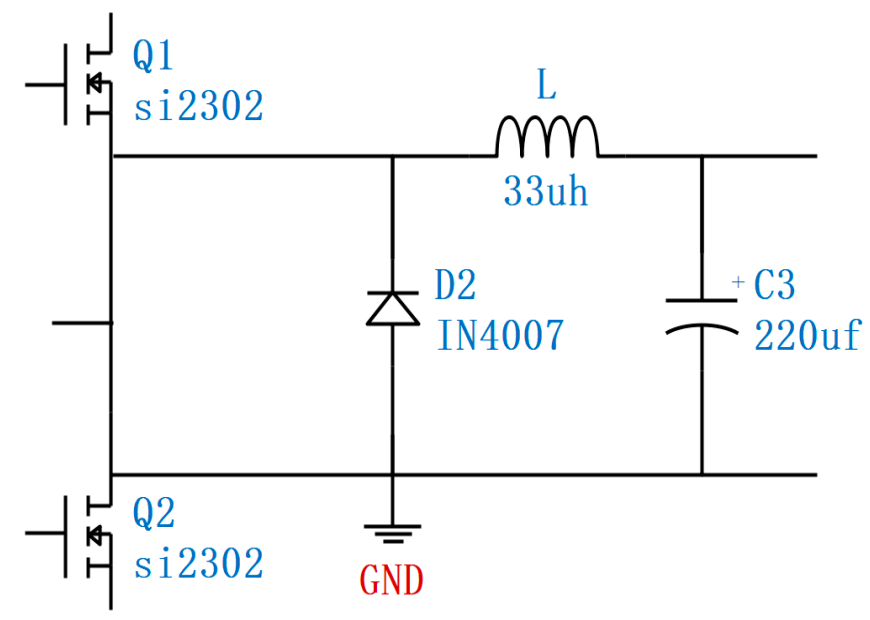

Figure 9. BUCK circuit.

The realization process of the MPPT algorithm of LCM-P\&O method is as follows: Firstly, a perturbation signal is applied through PWM, then a load current will be generated by the BUCK circuit. By monitoring the change of load current and photovoltaic cell input current, it can be determined whether to increase or reduce PWM in the next PWM regulation process. Considering that the change of light intensity is generally slow, to reduce the energy loss caused by the microcontroller unit(MCU) calculation, as with data acquisition, the maximum power point tracking is generally adjusted once every $5 \mathrm{~min}$.

\subsubsection{Experiment and Analysis under Constant Voltage Source Input}

The experimental design of MPPT circuit efficiency with constant voltage input is shown in Figure 10. The direct current(DC) constant voltage source is used to replace the photovoltaic cell to access the input of the MPPT circuit, the data of input current, load part current, and voltage at the output of DC constant voltage source are recorded by an oscilloscope. According to the measured voltage and current data, the power and tracking efficiency of the MPPT circuit can be calculated. Relevant experimental data and corresponding calculated values are shown in Table 1. 


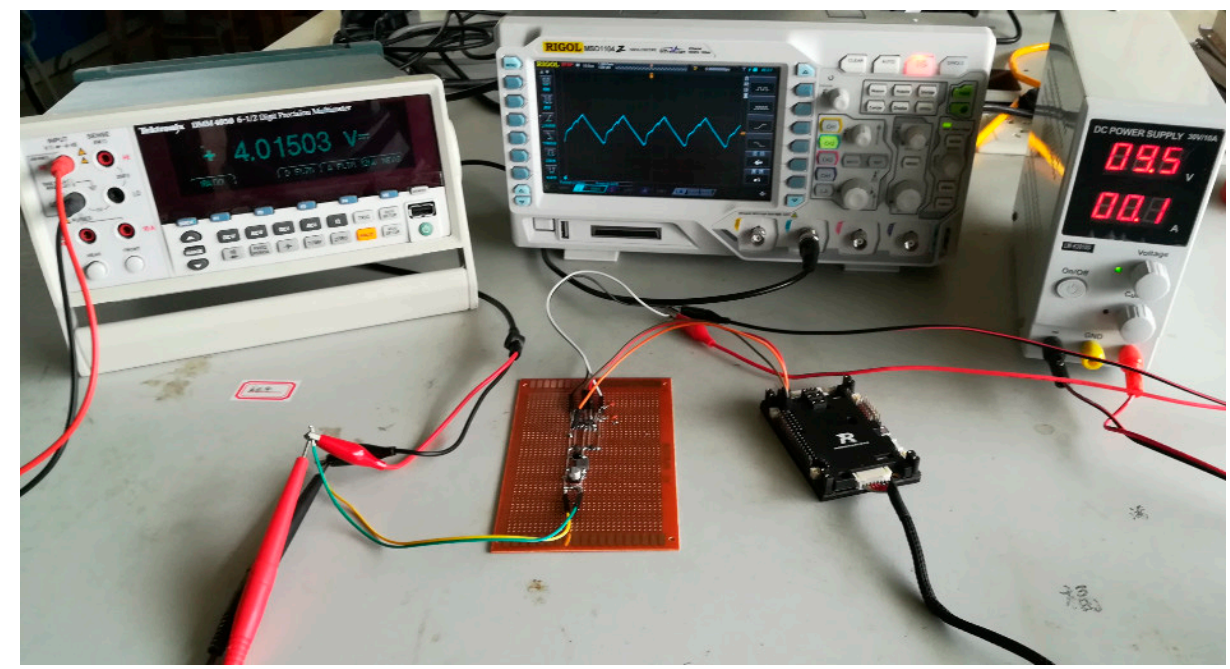

Figure 10. Experiment of MPPT circuit efficiency with constant voltage source input.

Table 1. Experimental data of MPPT circuit efficiency with constant voltage source input (LCM-P\&O method with fixed step size/LCM-P\&O method with variable step size).

\begin{tabular}{ccccc}
\hline $\begin{array}{c}\text { Input Voltage } \\
(\mathbf{V})\end{array}$ & $\begin{array}{c}\text { Input current } \\
(\mathbf{m A})\end{array}$ & $\begin{array}{c}\text { Output Voltage } \\
(\mathbf{V})\end{array}$ & $\begin{array}{c}\text { Output Current } \\
(\mathbf{m A} \mathbf{)}\end{array}$ & $\begin{array}{c}\text { Tracking } \\
\text { Efficiency (\%) }\end{array}$ \\
\hline $12 / 12$ & $115 / 115$ & $4.20 / 4.19$ & $297 / 298$ & $90.39 / 90.47$ \\
$11 / 11$ & $109 / 109$ & $4.17 / 4.16$ & $261 / 262$ & $90.77 / 90.90$ \\
$10 / 10$ & $102 / 102$ & $4.20 / 4.13$ & $220 / 225$ & $90.56 / 91.10$ \\
$9 / 9$ & $95 / 95$ & $4.19 / 4.09$ & $185 / 190$ & $90.67 / 90.89$ \\
$8 / 8$ & $84 / 84$ & $4.21 / 4.11$ & $146 / 150$ & $91.47 / 91.74$ \\
\hline
\end{tabular}

In Table 1, the power of DC constant voltage source decreases with the decrease of the DC constant voltage source voltage. At the same time, the voltage at the load end is almost unchanged, the current at the load end is gradually reduced, and the load power is also gradually reduced. We can also see that the tracking efficiency of the two methods is stable at about $90 \%-92 \%$, and the average tracking efficiency of the LCM-P\&O method with variable step size is $91.02 \%$, slightly higher than that of the LCM-P\&O method with fixed step size of $90.77 \%$, which meets the design requirements of the photovoltaic cell efficiency tracking.

\subsubsection{Experiment and Analysis under Indoor Fluorescent Lamp Illumination}

In the experiment, by adjusting the brightness of the fluorescent lamp to achieve the purpose of adjusting the light intensity of the photovoltaic cell, the work efficiency of the MPPT circuit of the photovoltaic cell can be tested. During the experiment, the input of photovoltaic cells and the voltage and current of after MPPT are detected, and the frequency is once per second. The light brightness of the fluorescent lamp is enhanced in about $70 \mathrm{~s}$, and the data is sent to the host computer through the communication module for recording. The experimental data under indoor fluorescent lamp illumination is shown in Figure 11. In Figure 11, there are five curves from top to bottom: The curve of photovoltaic cell voltage, the curve of photovoltaic cell current, the curve of voltage after BUCK circuit, the curve of current after BUCK circuit, and the curve of MPPT circuit efficiency. 


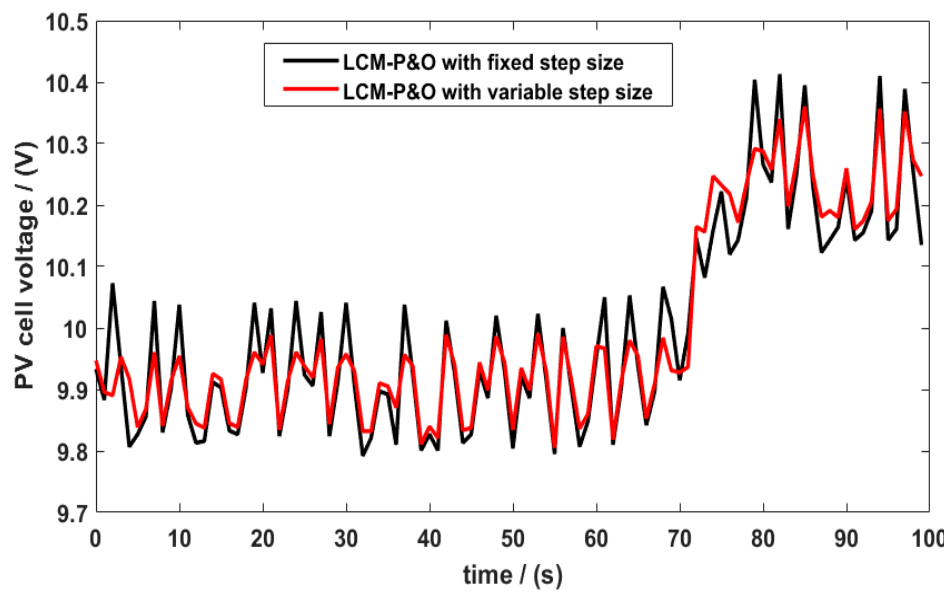

(a)

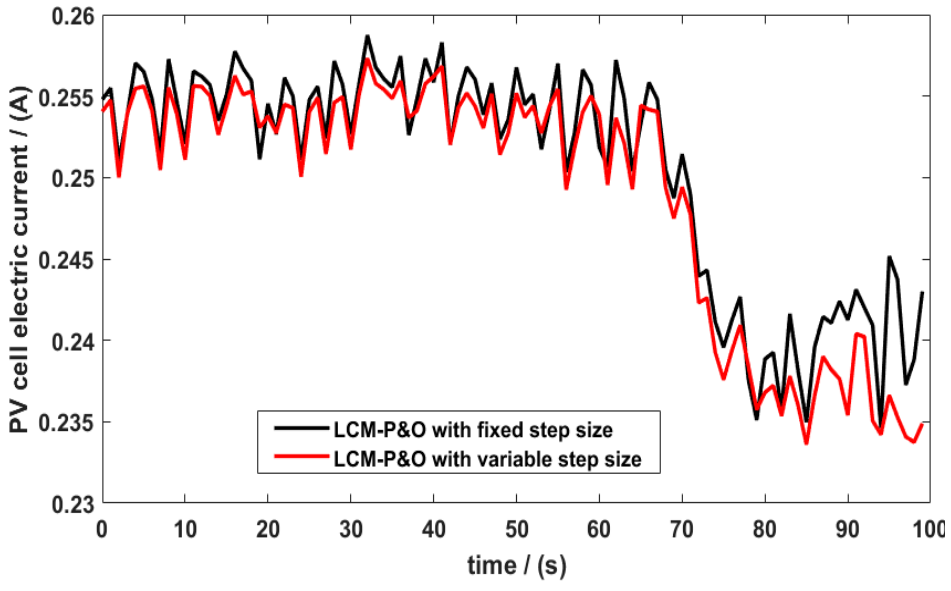

(b)

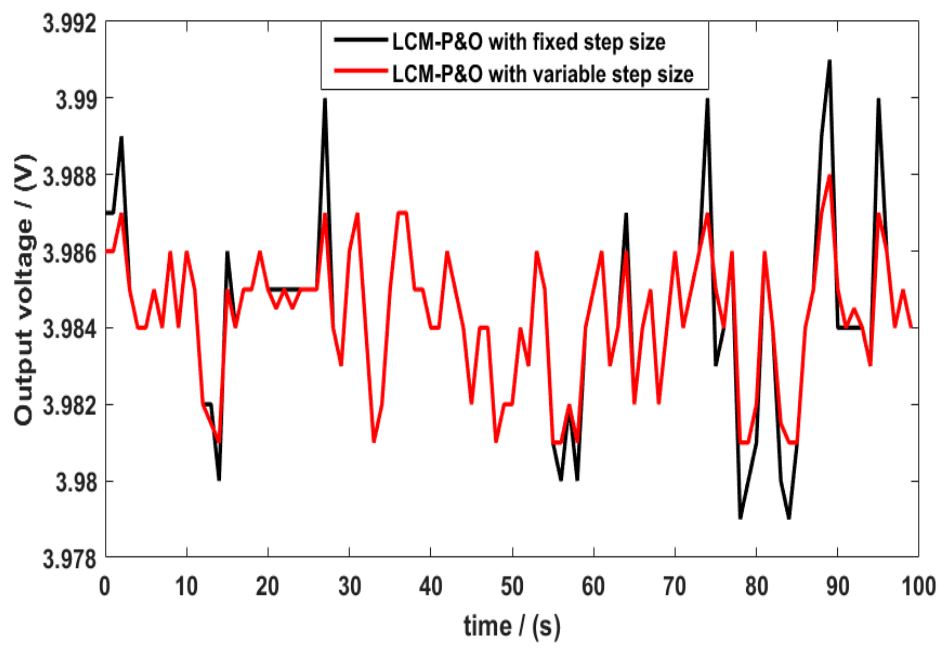

(c)

Figure 11. Cont. 


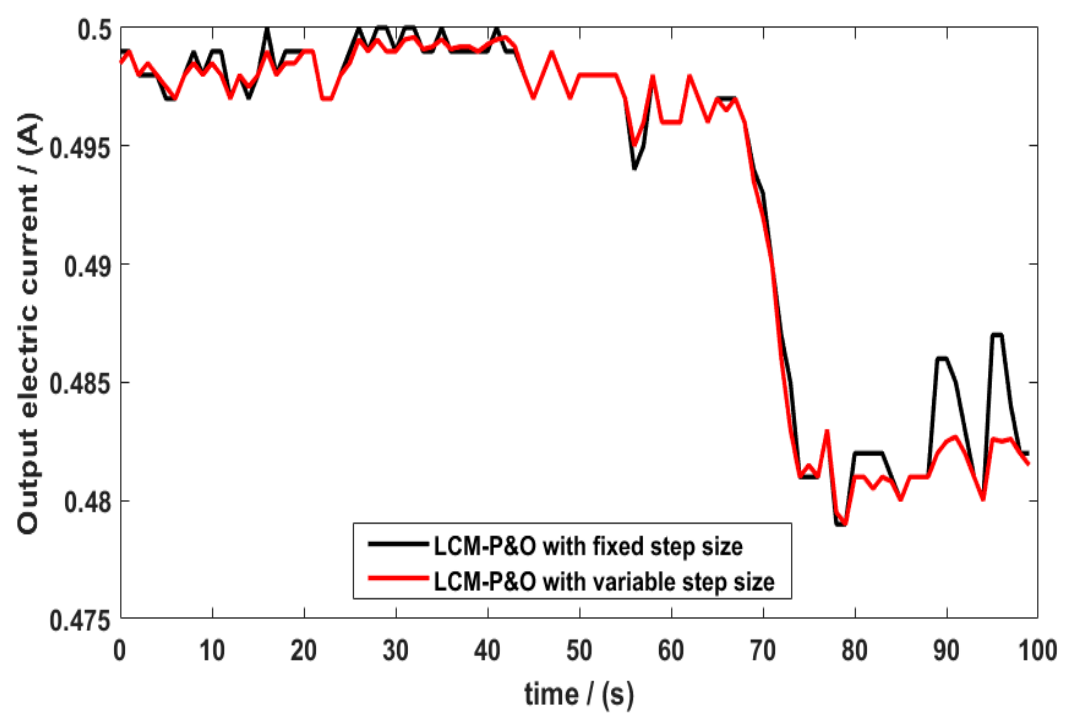

(d)

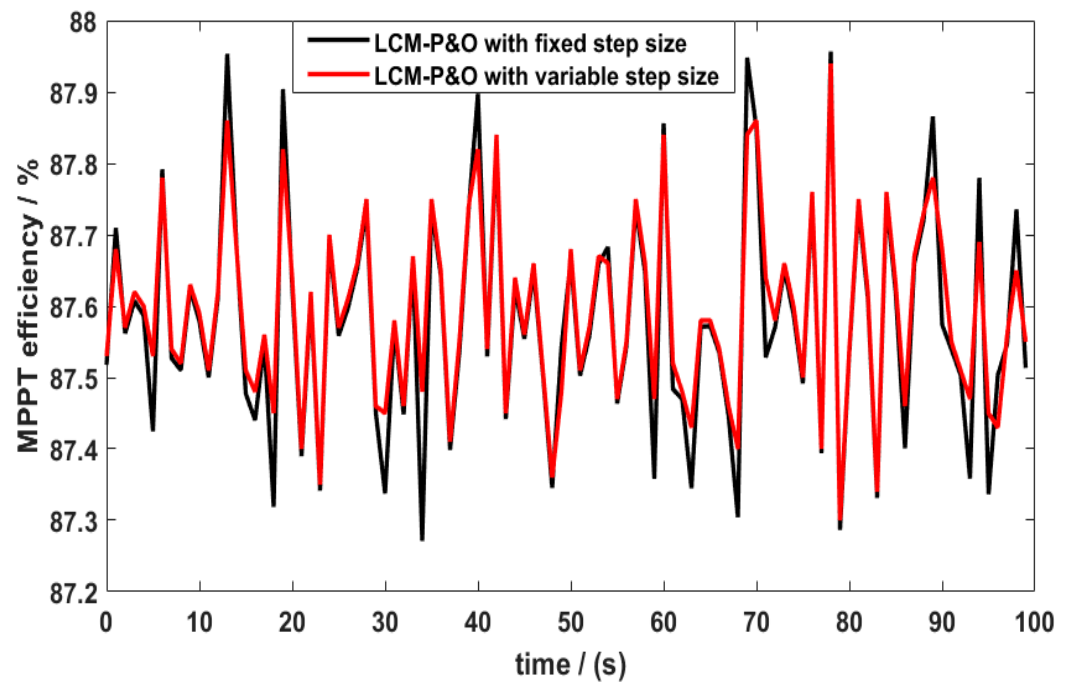

(e)

Figure 11. Experiment of MPPT circuit efficiency with indoor fluorescent lamp illumination. (a) Curve of photovoltaic cell voltage; (b) curve of photovoltaic cell current; (c) curve of voltage after BUCK circuit; (d) curve of current after BUCK circuit; and (e) curve of MPPT circuit efficiency.

In Figure 11a,b, there is no significant difference in the input voltage or current between the two MPPT circuits. Additionally, when the brightness of the fluorescent lamp is set at a low level, the input voltages of the photovoltaic cells are about $9.9 \mathrm{~V}$, and the input currents of the photovoltaic cells are about $0.253 \mathrm{~A}$. When the brightness of the fluorescent lamp increases to a higher level, the input voltages of the photovoltaic cells of two MPPT circuits increase to about $10.25 \mathrm{~V}$, and the input currents decrease to about $0.235 \mathrm{~A}$. This is because, with the increase of light intensity, the input voltage of photovoltaic cell increases, which makes the input current decrease, ensuring the optimal regulation of input energy. It can be seen from Figure 11c that the output voltages of two MPPT circuits do not change obviously before or after the illumination changes, and still fluctuates around $3.985 \mathrm{~V}$, which indicates that the BUCK circuit has a good voltage stabilizing effect. It can be seen from Figure $11 \mathrm{~d}$ that, after changing the brightness of the fluorescent lamp, the output currents of two MPPT circuits can quickly reach a new stable state, which shows that the tracking stability of the designed MPPT circuits 
are good. Additionally, it can be seen from Figure 11e that the MPPT efficiency curve of LCM-P\&O method with fixed step size fluctuates about $87.48 \%$, and the MPPT efficiency curve of the LCM-P\&O method with variable step size fluctuates about $87.59 \%$. The results show that the MPPT circuits have higher tracking efficiency and are less affected by the change of external conditions.

Compared with the simulation results in Section 4.2.2, the average efficiencies of two MPPT algorithms in the simulation experiment are $90.77 \%$ and $91.02 \%$, respectively, while the average efficiencies of MPPT circuits in the actual circuit experiment are $87.48 \%$ and $87.59 \%$, respectively. There are some gaps between the results of the simulation experiment and that of the actual circuit experiment. The main reasons for the lower efficiency of the actual circuit experiment are as follows: (1) in the actual circuit experiment, because the communication module is always in the sending state, the circuit energy consumption will increase more. (2) As the BUCK circuit and MPPT circuit have their loss, this will also lead to the increase of energy loss of the whole circuit. However, we see that the efficiencies of the actual MPPT circuit experiment and the MPPT algorithm simulation experiment are all higher, which shows that the circuit energy consumption of this design is low and meets the application requirements of WSN.

\section{Conclusions}

In this paper, the output characteristic of photovoltaic cell is analyzed. Additionally, a LCM-P\&O method with variable step size is proposed, which is suitable for self-powered systems of WSN. Further, the hardware circuit of the proposed algorithm based on the BUCK circuit is designed. The advantages of the proposed algorithm are verified by a simulation experiment and an actual circuit experiment. The following conclusions are drawn:

(1) The principle of the traditional P\&O method is simple and easy to realize. The traditional LCM method only needs to maximize the load current to realize the maximum output power of photovoltaic cell. Combining the advantages of these two algorithms, a novel LCM-P\&O method with variable step size is proposed in our study. Compared to some existing algorithms, the proposed algorithm does not need to calculate power to determine the direction of perturbation, only needs to sample the load current to determine the direction of disturbance, and the MPPT is realized by dynamically adjusting the reference current value. The proposed algorithm can give attention to both the tracking speed and the tracking accuracy, and has lower energy consumption.

(2) Based on the BUCK Circuit, the circuit design and implementation method of the LCM-P\&O method are presented. The effectiveness of the proposed algorithm is verified by the actual MPPT circuit test and analog experiment. The experimental results show that the designed circuit has the characteristics of low power consumption, high efficiency, good stability, and easy realization. The experimental data of constant voltage source input show that the lowest tracking accuracy of the MPPT circuit can reach $90.47 \%$, and the highest tracking accuracy can reach $91.74 \%$. The experimental results of fluorescent lamp illumination show that the average tracking accuracy of MPPT circuit can reach $87.59 \%$, the highest tracking accuracy can reach $87.97 \%$. The circuit design and implementation methods have certain practical engineering value.

(3) From the actual circuit MPPT experiment, it is also found that although the MPPT efficiency waveform of the LCM-P\&O method with variable step size is more stable than that of LCM-P\&O method with fixed step size, the MPPT efficiency increase is only less than $0.11 \%$, and the efficiency improvement effect is not obvious. The main reasons for this problem are as follows: (i) in the experiment, the light source of the photovoltaic panel is provided by the simulated light source, and the light value will fluctuate slightly. (ii) When photovoltaic effect is produced, the temperature of photovoltaic cell will rise slightly. (iii) The effect of the algorithm in practical application needs to be improved. How to solve these practical problems and to improve the efficiency of MPPT is the main content of our future research. 
Author Contributions: Conceptualization, L.Z.; Data curation, P.C. and S.Z.; Simulation, Z.W. and P.C.; Physical verification, Z.W. and P.C.; writing-original draft preparation, S.Z. and P.C.; writing-review and editing, P.C. and L.Z.; supervision, L.Z. All authors have read and agreed to the published version of the manuscript.

Funding: This work was funded by National Natural Science Foundation of China (No. 61741303), and the Scientific Research Basic Ability Enhancement Program for Young and Middle-aged Teachers of Guangxi (No.2019KY0300).

Acknowledgments: The authors would like to thank for the comments from many reviewers to improve this work.

Conflicts of Interest: The authors declare no conflict of interest.

\section{References}

1. Wang, C.; Li, J.; Yang, Y.; Ye, F. Combining solar energy harvesting with wireless charging for hybrid wireless sensor networks. IEEE. Trans. Mob. Comput. 2017, 17, 560-576. [CrossRef]

2. Zhu, Y.; Kim, M.K.; Wen, H. Simulation and Analysis of Perturbation and Observation-Based Self-Adaptable Step Size Maximum Power Point Tracking Strategy with Low Power Loss for Photovoltaics. Energies 2019, 12, 92. [CrossRef]

3. Macaulay, J.; Zhou, Z. A Fuzzy Logical-Based Variable Step Size P\&O MPPT Algorithm for Photovoltaic System. Energies 2018, 11, 1340.

4. Nallusamy, R.; Duraiswamy, K. Solar powered wireless sensor networks for environmental applications with energy efficient routing concepts: A review. Inf. Technol. J. 2011, 10, 1-10. [CrossRef]

5. Zhang, X.; Yu, S.S.; Yin, L.L.; Zhong, W.W.; Yang, Z.J. P\&O MPPT algorithm with variable step size based on dichotomy. Chin. J. Power Sources 2018, 42, 536-539.

6. Vincheh, M.R.; Kargar, A.; Markadeh, G.A. A Hybrid Control Method for Maximum Power Point Tracking (MPPT) in Photovoltaic Systems. Arab. J. Sci. Eng. 2014, 39, 4715-4725. [CrossRef]

7. Femia, N.; Petrone, G.; Spagnuolo, G.; Vitelli, M. Optimization of Perturb and Observe Maximum Power Point Tracking method. IEEE Trans. Power Electron. 2005, 20, 963-973. [CrossRef]

8. Masoum, M.A.S.; Dehbonei, H.; Fuchs, E.F. Theoretical and experimental analyses of photovoltaic systems with voltage and current-based maximum power-point tracking. IEEE Trans. Energy Convers. 2002, 17, 514-522. [CrossRef]

9. Dileep, G.; Singh, S.N. Maximum power point tracking of solar photovoltaic system using modified perturbation and observation method. Renew. Sustain. Energy Rev. 2015, 50, 109-129. [CrossRef]

10. Yin, L. Design of Dynamically Self-Adaptive Load Current Maximization Technique in PV Cell MPPT Systems. Master's Thesis, Zhejiang University, Hangzhou, Zhejiang, China, 2012.

11. Ibnelouad, A.; Kari, A.E.; Ayad, H.; Mjahed, M. Comparison of Fuzzy and Neural Networks Controller for MPPT of Photovoltaic Modules. In Innovations in Smart Cities and Applications, Proceedings of the 2nd Mediterranean Symposium on Smart City Applications, Tangier, Morocco, 25-27 October 2017; Springer: Cham, Switzerland, 2017; pp. 515-527.

12. Mei, Q.; Shan, M.W.; Liu, L.Y.; Guerrero, J.M. A novel improved variable step-size incremental-resistance MPPT method for PV systems. IEEE Trans. Ind. Electron. 2010, 58, 2427-2434. [CrossRef]

13. Hang, F.H.; Yang, W.; Zhu, W.Y. Analysis and improvement of MPPT disturbance observer method for PV system. Power Syst. Prot. Control. 2014, 42, 110-114.

14. Zheng, B.W.; Cai, F.H.; Wang, W. Analysis and research of MPPT algorithm for a single-stage PV grid-connected power generation system. Trans. China Electrotech. Soc. 2011, 26, 90-96.

15. Veerachary, M.; Senjyu, T.; Uezato, K. Neural-network-based maximum-power-point tracking of coupled-inductor interleaved- boost- converter-supplied PV system using fuzzy controller. IEEE Trans. Ind. Electron. 2003, 50, 749-758. [CrossRef]

16. Chen, C.B.; Jing, Z.; Gao, S. Study on An Improved Variable Step-size MPPT Algorithm for Restraining Steady Oscillation. Power Capacit. React. Power Compens. 2019, 40, 184-189.

17. Hosseini, S.; Taheri, S.; Farzaneh, M.; Taheri, H. A High-Performance Shade-Tolerant MPPT Based on Current-Mode Control. IEEE Trans. Power Electron. 2019, 34, 10327-10340. [CrossRef]

18. Xiong, Y.S.; Yu, L.; Xu, J.M. MPPT control of photovoltaic generation system combining constant voltage method with perturb-observe method. Electr. Power Autom. Equip. 2009, 9, 85-88. 
19. Ramos-Hernanz, J.; Lopez-Guede, J.M.; Barambones, O.; Zulueta, E.; Fernandez-Gamiz, U. Novel control algorithm for MPPT with Boost converters in photovoltaic systems. Int. J. Hydrog. Energy 2017, 42, 17831-17855. [CrossRef]

20. Messalti, S.; Harrag, A.; Loukriz, A. A new variable step size neural networks MPPT controller: Review, simulation and hardware implementation. Renew. Sustain. Energy Rev. 2017, 68, 221-233. [CrossRef]

21. Mousa, H.H.; Youssef, A.R.; Mohamed, E.E. Variable step size P\&O MPPT algorithm for optimal power extraction of multi-phase PMSG based wind generation system. Electr. Power Energy Syst. 2019, 108, $218-231$.

22. Moon, S.; Kim, S.J.; Seo, J.W.; Park, J.H.; Park, C.; Chung, C.S. Maximum power point tracking without current sensor for photovoltaic module integrated converter using Zigbee wireless network. Int. J. Electr. Power Energy Syst. 2014, 56, 286-297. [CrossRef]

23. Leedy, A.W.; Guo, L.P.; Aganah, K.A. A constant voltage MPPT method for a solar powered boost converter with DC motor load. In Proceedings of the 2012 IEEE Southeastcon, Orlando, FL, USA, 15-18 March 2012; pp. 1-6.

24. Yin, L.; Wu, X.; Chen, C.L.; Cheng, L.C. Dynamically self-adaptive load current maximization technique for maximum power point tracking in photovoltaic arrays. In Proceedings of the 2011 IEEE International Conference of Electron Devices and Solid-State Circuits, Tianjin, China, 17-18 November 2011; pp. 1-2.

25. Xiao, L.X.; He, Y.T.; Peng, Y.H.; Liu, J.H.; Li, L. Theory and Experiment Study on Temperature Effects on Photovoltaic Cell Conversion Characteristics. Electr. Meas. Instrum. 2014, 51, 62-66.

26. Hu, C.W.; Li, B.G.; Wang, L.M.; Teng, N.N. Matlab/Simulink simulation research on a simplified mathematical model of PV cells. Renew. Energy Resour. 2013, 31, 20-24.

27. Guo, C.L.; Zhang, S.S.; Li, M.; Du, H.C. Analysis on mathematic model of photovoltaic panels and MPPT control simulation. Chin. J. Power Sources 2014, 38, 1640-1643.

28. Raghunathan, V.; Schurgers, C.; Park, S.; Srivastava, M.B. Energy-aware wireless microsensor networks. IEEE Signal Process. Mag. 2002, 19, 40-50. [CrossRef]

(C) 2020 by the authors. Licensee MDPI, Basel, Switzerland. This article is an open access article distributed under the terms and conditions of the Creative Commons Attribution (CC BY) license (http://creativecommons.org/licenses/by/4.0/). 